\title{
Laços transatlânticos: o salazarismo e as relações entre Brasil e Portugal na Revista Luso-Brasileira (1961-1979)
}

Cristina Iuskow ${ }^{\mathbf{I}}$

Resumo: este artigo tem como objetivo tratar da inserção da Revista Luso Brasileira na cidade de Florianópolis nas décadas de 1960 e 1970. Esta foi uma publicação catarinense, que circulou entre 1961 e 1979, fundada pelo português Mario Fernandes Dias, emigrado de Portugal para Florianópolis em 1958. Publicação com 20 páginas e uma tiragem de 1000 exemplares por edição, que era na maioria das vezes bimestral. Contemplava diversos assuntos desde culinária à vida política de Portugal e do Brasil, entremeados por anúncios de comércio local. Seus mil exemplares eram enviados ainda para Portugal, Angola, Cabo Verde e outras cidades do Brasil. Buscarei aqui compreender as temáticas tratadas pela revista e as relações estabelecidas com os regimes de Portugal e Brasil, nas suas variações políticas, e, além disso, perceber como a publicação se relacionava com a política e comunidade local, por meio do tratamento de periódicos, percebidos aqui como fonte essencial no estudo da história do tempo presente.

Palavras-chave: Revista Luso-Brasileira; Relações Brasil-Portugal; Salazarismo; imprensa.

\section{Transatlantic ties: Salazarism and relations between Brazil and Portugal in the Luso-Brazilian Magazine (1961-1979)}

\begin{abstract}
This article aims to address the insertion of the Luso - Brazilian Magazine in the city of Florianópolis in the 1960s and 1970s. It was published in Santa Catarina between 1961 and 1979, founded by Portuguese Mario Fernandes Dias, who emigrated from Portugal to Florianópolis in 1958. Publication with 20 pages and a print run of 1000 copies per edition, which was mostly bimonthly. It contemplated diverse subjects from culinary to the political life of Portugal and Brazil, interspersed by ads of local commerce. Its thousand copies were still sent to Portugal, Angola, Cape Verde and other cities of Brazil. I will try to understand the themes dealt with by the journal and the relations established with the regimes of Portugal and Brazil in their political variations and, in addition, to understand how the publication related to the local politics and community, through the treatment of periodicals, perceived here as an essential source in the study of the history of the present time.
\end{abstract}

Keywords: Luso-Brazilian Journal; Brazil-Portugal relations; Salazarism; press.

Artigo recebido em 13/05/2017 e aprovado em 05/06/2017. 


\section{LAÇOS TRANSATLÂNTICOS: O SALAZARISMO E AS RELAÇÕES ENTRE BRASIL E PORTUGAL NA REVISTA LUSO-BRASILEIRA (1961-1979)}

\section{CRISTINA IUSKOW}

A provinciana cidade de Florianópolis, capital do Estado de Santa Catarina, em inícios da década de 1960, nada parecia, para um viajante desavisado, com o aspecto que se esperaria de uma capital. Perdida entre um passado em que fora um entreposto comercial e sede de empresas atacadistas que entraram em decadência junto com o movimento portuário e um presente em que a muito custo tentava inserir-se no cenário industrial e de progresso que o país principiava a percorrer, a capital catarinense ainda iria traçar um longo caminho até conseguir alguma visibilidade nacional explorando seus recantos paisagísticos. Nesta ilha ao Sul do Brasil, em 1959, desembarcou um português que ao que tudo indica, vinha ao encontro de uma moça da cidade que esperava conhecer. Esta é a história que fiquei conhecendo em conversa informal na sala da casa do sr. Mario Fernandes Dias, com sua esposa, no ano de 2009. Sua chegada cheia de expectativas se tornaria uma longa história de parcerias na vida pessoal e profissional. Profissional, pois em maio de 1961, com uma equipe de escritores e jornalistas, juntamente com sua esposa Terezinha Cascaes Dias, Mario Fernandes publicará o primeiro número da Revista Luso-Brasileira em Florianópolis.

Ao ter o primeiro contato com esta revista na Biblioteca Pública do Estado de Santa Catarina, questionei-me sobre qual o intuito de uma revista que pretendia ser $U m$ laço de amizade entre Brasil e Portugal ser publicada na longínqua e quase imóvel Florianópolis dos anos de 1960. No aspecto midiático e editorial a cidade não possuía muitas opções, alguns jornais - O Estado, A Gazeta, Imprensa Nova, Diário da Tarde - e pouquíssimas revistas circulavam pela cidade naqueles anos. Algumas emissoras de rádios também faziam a comunicação entre os moradores: Rádio Santa Catarina, Rádio Jornal A verdade, Rádio Anita Garibaldi e Diário da Manhã. Ao mesmo tempo em que a revista haveria de ter um público escasso, também teria dificuldades na sua edição. Ao acompanhar a publicação mês a mês, e perceber por meio da sua leitura, o diálogo estabelecido com os leitores, ao expor as dificuldades e as conquistas realizadas nas duas décadas de publicação, pude perceber que esta era uma atividade que tinha êxitos. Aos poucos, os anunciantes da cidade compunham as páginas da revista, o público leitor enviava suas cartas elogiosas bem como instituições pelo Brasil e fora dele agradeciam o recebimento de números da revista com elogios às matérias, fazendo votos de que a amizade entre os dois países permanecesse.

A ligação da revista com Portugal, para além da nacionalidade de seu editor, seria uma interrogação recorrente ao pesquisá-la, que leva necessariamente à questão de seu posicionamento em relação ao regime português de Oliveira Salazar. Para essa questão a resposta não é tão simples e vai sendo respondida aos poucos com a ampliação do trabalho, em meio a novos indícios, novas perguntas sem respostas, pistas que vão aparecendo no caminho da escrita e da investigação. Afinal, seria preciso imiscuir-se nos arquivos, nos documentos e nas páginas da Revista Luso-Brasileira para conseguir responder as várias questões que se apresentavam.

A publicação foi fundada em maio de 1961, e tinha periodicidade mensal, no entanto era publicada bimensalmente em alguns períodos. Seu diretor era Mario Fernandes Dias, e tinha como colaboradores Therezinha Cascaes Dias, Waldemiro Cascaes, Francisco Mascarenhas, Samuel Brito Ribeiro e Íris Fadel, em um primeiro momento. Em suas 20 páginas com imagens em poucas cores - vermelha, verde, azul e amarela - distribuíam-se textos variados e densos num tamanho pouco maior que A4. É 


\section{LAÇOS TRANSATLÂNTICOS: O SALAZARISMO E AS RELAÇÕES ENTRE BRASIL E PORTUGAL NA REVISTA LUSO-BRASILEIRA (1961-1979)}

\section{CRISTINA IUSKOW}

notável ao longo de seus números a ausência de um padrão na disposição das matérias no periódico, bem como das capas e localização do expediente da revista, por exemplo. Seu slogam inicial é Um laço de amizade entre Brasil e Portugal, todavia este também terá modificações no decorrer do tempo de publicação. O preço a que era vendida no Brasil em maio de 1961 eram 30 cruzeiros, sendo que a assinatura de 12 números era de 200 Cruzeiros e a de 6 números 100 Cruzeiros. O local de impressão consta como Impressora Modelo, propriedade de Orivaldo Stuart.

Ao visualizar o interior da revista e observar seu conteúdo, o leitor perceberá que não há uma padronização nas seções do periódico, mas que diferem de acordo com conteúdos, na parte gráfica, no tipo de letras e na disposição das matérias. O local do sumário não é padronizado na revista, por exemplo. A seção Portugal em Marcha e $O$ Brasil em Marcha são apresentadas no primeiro número, no segundo são suprimidas, substituídas pelo título Santa Catarina em Marcha. Essas e outras variações ocorrerão ao longo de todos os números da publicação o que demonstra uma falta de preocupação dos editores para com a padronização e constância das seções na revista.

Em seu primeiro número, em maio de 1961, a Revista Luso-Brasileira adentra o espaço dos periódicos de Florianópolis como se já estivesse circulando pelas bancas da cidade. Seu primeiro número aborda a comemoração do dia das mães, sem notas na capa que tragam qualquer menção a uma nova revista na praça. Envolve-se, a partir desse tema, nas preocupações dos habitantes da cidade naquele mês. Com a capa voltada para as mães podemos chegar a uma conclusão precipitada: a Revista LusoBrasileira é uma revista voltada ao público feminino. Mas, essa impressão esmaece conforme novas matérias surgem na publicação.

Na capa, ao lado da foto de uma mulher com um bebê ao colo, numa página com dimensão de $31 \mathrm{~cm}$ x $24 \mathrm{~cm}$, em letras vermelhas sobre o fundo branco, é apontada a lista com os temas encontrados no interior da revista, entre eles cito alguns: Belezas e Costumes de Portugal; Falam os Professores; O Brasil em Marcha; Controvérsias da História; Santa Catarina em Foco; A História de Juliana; Aviadores Célebres; Página Jurídica; Infante Santo; Crítica Literária. Temas diversos, que inicialmente indicam o público a que se direciona e as temáticas que serão abordadas. Lembro aqui o que aponta Ana Luiza Martins sobre o trabalho com revistas, em que a importância desse tipo de impresso como testemunho vale "[...] se levarmos em consideração as condições de sua produção, de sua negociação, de seu mecenato propiciador, das evoluções técnicas a que se assistia e, sobretudo, da natureza de capitais envolvidos". "Como testemunho do período é uma documentação relevante, mas não pode ser considerada como única fonte para compreender a complexidade das relações entre Brasil e Portugal. E, além disso, é preciso mais do que compreender os textos publicados na revista, mas também as condições para sua publicação, seu financiamento, sua feitura.

$\mathrm{Na}$ viragem da página, algumas informações apresentam-se e, assim, é possível compreender aspectos significativos da publicação. Começando com a mudança no subtítulo, que na contracapa se apresenta como: A Revista para brasileiros $e$ portugueses. As chamadas mostram a intenção da revista e o seu direcionamento a brasileiros $e$ portugueses. Ainda nessa coluna à esquerda, de cima a baixo, após citar seus colaboradores apresenta a informação: com a aprovação de Ramiro Valadão, do Secretariado Nacional de Informação de Lisboa (SNI) e do jornal Diário Popular ${ }^{I I I}$ de Lisboa. Chama bastante atenção neste ponto a aprovação do SNI, demonstrando a priori 


\section{LAÇOS TRANSATLÂNTICOS: O SALAZARISMO E AS RELAÇÕES ENTRE BRASIL E PORTUGAL NA REVISTA LUSO-BRASILEIRA (1961-1979)}

\section{CRISTINA IUSKOW}

uma interferência na publicação e edição da revista em Florianópolis. Ramiro Machado Valadão foi um jornalista e também político português e na época Diretor dos Serviços de Informação do Secretariado Nacional da Informação. Cargo de relevância, o que demonstra que houve negociações para dar início à publicação da RLB $^{\text {IV }}$ com as pessoas responsáveis pela propaganda oficial em Portugal. Apresenta-se aqui um indício que demonstra que em pouco tempo de estadia na cidade, Mario Fernandes conseguiu as conexões necessárias para dar início à elaboração e publicação da revista, em Santa Catarina e em Portugal. Infere-se daí que os contatos já haviam sido feitos em Portugal, e aqui chegando a ideia de publicar uma revista já estava sendo gestada. Os documentos escritos aos poucos vão se colocando como vozes dessa história.

Como uma espécie de editorial e com um texto que aí sim se apresenta como um anúncio que mostra a que veio a Revista Luso-Brasileira, o texto com o título A Nossa Missão explicita as aspirações da publicação:

Fortalecer os laços de amizade entre o Brasil e Portugal, é o nosso principal objetivo. Somos novatos no jornalismo, embora o autor dessas linhas seja um novelista conhecido na terra portuguesa. [...] com a ajuda de Deus, iremos pelo Brasil a fora, pôr esses retalhos de terra onde se fala a nossa língua, procurando dar a conhecer a nossa revista; Portugal terá aqui o seu cantinho bem merecido e ficará a par da marcha triunfal da nossa terra brasileira. [...]. ${ }^{\mathrm{V}}$

Nessa feição inicial da revista, é perceptível a origem portuguesa do editor e sua ligação com o ideário salazarista. Os textos apresentam aos poucos o caráter conservador do periódico. O fato de ter a aprovação do SNI torna essa publicação $a$ priori apoiadora do regime de Salazar, mas para além dessa chancela, a posição política vai aparecendo nas matérias número a número. No que diz respeito ao posicionamento diante da política no Brasil sua postura política é de assentimento e, pode-se afirmar ainda, que é uma postura de apartar-se das discussões sobre o cenário político nacional.

Há um intento em demonstrar que seus elaboradores não são profissionais, peritos no trabalho jornalístico, mas possuidores de uma missão que é a de unir os dois povos, portugueses e brasileiros, trabalhando juntos na publicação com o objetivo de fazer com que os povos trabalhem juntos e fortaleçam seus laços. Portugal terá um espaço naquelas páginas e conhecerá o progresso brasileiro. "Progresso" que é importante se propagar num momento de tensões nas colônias portuguesas, "progresso", argumento que se poderia usar na negociação com os movimentos de independência, pois poderiam vislumbrar no Brasil o seu horizonte de expectativas ${ }^{\mathrm{VI}}$ diante de um presente desolador.

A missão proposta pelo primeiro editorial da RLB, ao se fazer uma incursão mais profunda sobre o papel do emigrante português, mais particularmente pelo português Mario Fernandes Dias, nos faz compreender o quão representativo para o projeto de emigração do Estado Novo este evento pode ser. Ao deixar Portugal, o emigrante não se desliga de seu país, leva o país consigo, dá seu apoio ao regime de onde quer que esteja. A emigração para o Brasil era incentivada, pois este seria considerado o "país irmão", expressão evocada para acentuar uma determinada relação que se busca construir entre os dois países e sua condição de dividirem grande parte de suas histórias e falarem a mesma língua. Para Portugal, sobretudo no contexto político da década de 1960, afirmar ter o Brasil como país irmão era uma forma de apresentar essa relação permeada de raízes, boas relações e familiaridade. Eduardo Lourenço, 


\section{LAÇOS TRANSATLÂNTICOS: O SALAZARISMO E AS RELAÇÕES ENTRE BRASIL E PORTUGAL NA REVISTA LUSO-BRASILEIRA (1961-1979)}

\section{CRISTINA IUSKOW}

escritor português, fala sobre esta relação, a qual não considera de nenhuma maneira tão próxima, lembra as diferenças entre o discurso português sobre o Brasil e a forma como o Brasil vê Portugal: "O discurso português sobre o Brasil [...] é uma pura alucinação nossa, que o Brasil - pelo menos desde há um século - nem ouve nem entende". VII Para o autor a distância que se colocou entre o Brasil e Portugal não é percebida da mesma maneira para os dois países, pois o Brasil se encontra bem mais distante de Portugal. Para o autor há motivos para os brasileiros comportarem-se como se fossem filhos de si mesmos. Não seriam os brasileiros os responsáveis por colocar "entre parênteses" as suas raízes portuguesas, como recusa da relação obcecante de uma origem vinda de outro lugar. São sim os próprios portugueses a fonte da diluição dos laços com Portugal, pois, afirma, ocorreu como se tivessem ido para o continente brasileiro para por lá se perderem, e lá se perderam. ${ }^{\text {VIII }}$ Os portugueses que chegaram ao Brasil se transformaram logo em brasileiros, não se constituíram num pai de um novo povo, mas eram eles os pais de si mesmos. Essa reflexão de Lourenço o leva a concluir que a comunidade luso-brasileira é um mito inventado unicamente pelos portugueses, e que não é minimamente vivida pelo lado de cá do Atlântico. Diante desse contexto é possível perceber que a luta pelo fortalecimento de laços entre brasileiros e portugueses é uma tarefa que vai contracorrente dos eventos históricos passados entre os dois países.

Neste sentido, no cenário de migração de portugueses para o Brasil, há um constante interesse em imprimir no português que emigra uma marca possível de ser transportada para qualquer local e que o lembrará de seu papel no interior do corpo da nação Portugal. Heloísa Paulo afirma que "O português, como 'cidadão, é, enfim, uma representação 'metafórica' da 'Nação', sendo a sua função referendar a acção do poder constituído". "IX Portanto, a função do português é uma só, estando fora ou dentro de Portugal. E continua: "[...] o Estado Novo vai recorrer a [...] meios para que a sua mensagem seja incorporada pelos portugueses emigrados. ${ }^{\mathrm{X}}$

Esta não será uma tarefa simples, pois para manter a influência e garantir a propaganda do regime em um país distante como o Brasil será necessário um engenhoso aparato institucional. Esse aparato se inicia já no país de origem, pois havia todo um conjunto de fiscalização do regime por meio de entrevistas a quem desejava emigrar, que impedia, por exemplo, a vinda de famílias inteiras para o Brasil, evitando assim que os laços com Portugal fossem cortados; também o estado de saúde era averiguado, mas mais importante ainda era a certificação de que os emigrantes fossem alfabetizados, sendo que em 1955 é criada a "exigência formal do exame da $3^{\text {a }}$ classe do então ensino primário elementar". XI Havia a preocupação de que os emigrados não "desprestigiassem a Nação"XII e não prejudicassem o "bom nome do país". Algo que é importante destacar é que os custos da viagem ao Brasil não eram baixos, e o processo não era simples. Uma viagem para o Brasil na década de 1950 era o equivalente a seis vezes o salário de um trabalhador de baixa renda em Portugal, além de outras taxas obrigatórias. Isto para dizer que "quem emigra está longe de ser o proletariado rural". XIII

Além das exigências e controle feitos ao emigrante ainda em Portugal, era preciso que as ligações continuassem na terra de destino. Para este fim, direcionados aos portugueses no exterior são utilizados panfletos de propaganda, boletins, folhetos informativos e também os discursos de propaganda. ${ }^{\text {XIV }}$ Tipos variados de mensagens para alertá-lo sobre a nova terra, consolá-lo por deixar Portugal e lembrar o emigrante das suas obrigações. Citando aqui um folheto de 1959 com o título Instruções para o 


\title{
LAÇOS TRANSATLÂNTICOS: O SALAZARISMO E AS RELAÇÕES ENTRE BRASIL E PORTUGAL NA REVISTA LUSO-BRASILEIRA (1961-1979)
}

\section{CRISTINA IUSKOW}

uso dos Portugueses que se destinam ao Brasil, um trecho se refere a Portugal, com o seguinte texto:

\begin{abstract}
O teu país não é, como muitos supõem, pequeno em extensão ou em homens. Hoje, constitui uma república unitária e corporativa, sob a égide de uma constituição que, agitando os símbolos que, ontem como hoje, o fizeram grande - Deus, pátria, família - vincula territórios e povos a uma só bandeira e a um só nome: Portugal. Tu o representas. ${ }^{\mathrm{XV}}$
\end{abstract}

Neste trecho várias inferências ao "português ausente" e distante, para o qual é importante recordar quando se dirige ao país de dimensões continentais como o Brasil, que Portugal não é um país pequeno, mas tão grande quanto aquele. Ao mesmo tempo observa que o país só é grande e uno porque ligado pelos símbolos Deus, pátria e família. E num tom imperativo alerta que o emigrante representa toda essa "grandeza" que é Portugal.

São mensagens que ao serem acessadas por quem deixou o país, possibilitam uma maior proximidade do regime português ao seu "representante" no Brasil. Cria-se por meio desses elementos, que apelam às raízes nacionais, ao patriotismo e à tese da afetividade histórica, um laço com o emigrado que ao mesmo tempo e discretamente o insere, ou melhor, não o deixa de fora das demandas políticas de Portugal com o Brasil. A referência à língua como o liame da comunidade luso-brasileira, o elemento central além de um passado histórico em comum, será algo com frequência citado em textos e discursos do Estado Novo. As histórias conectadas entre esses dois povos serão possibilitadas e reforçadas porque havia e haveria sempre o inexorável fator linguístico. Utilizá-lo como elemento formador de "laços" entre brasileiros e portugueses será crucial para fortalecimento da comunidade luso-brasileira. A importância da língua está no

[...] seu papel na comunicação e na interconectividade, por ser um veículo de transmissão de ideias e de inovações tecnológicas, mas também de dados culturais como a herança e a consanguinidade, os laços de familiaridade e os sistemas de coesão social sedimentados ao longo do passado histórico. ${ }^{\text {XI }}$

Utilizar esse veículo é uma forma de criar a comunidade luso-brasileira, que não corresponde a uma realidade naturalizada tão somente por haver portugueses $\mathrm{e}$ brasileiros que se relacionam no interior do Brasil ou Portugal, mas que era preciso construí-la, criar um sentimento de pertencimento a esta comunidade.

Para além do Tratado de Amizade e Consulta assinado em 1951, firmado no âmbito das relações governamentais, a amizade, elemento fortalecedor da comunidade, deveria ser construída por outros meios, meios que fossem capazes de produzir um sentimento de ligação a uma comunidade que não deveria ser somente um ajuntamento dos falantes da língua portuguesa, mas que fossem unidos por outros interesses. $\mathrm{O}$ intenso fluxo emigratório português nos séculos XIX e XX, refere Lang, levou Portugal a ter um conceito mais abrangente de país considerando além do território, os falantes da língua portuguesa. Este é um "conceito de nação dispersa, alargada, extensiva a todo local onde existam comunidades portuguesas, fazendo com que as relações de Portugal com tais comunidades se acentuem". XVII 


\section{LAÇOS TRANSATLÂNTICOS: O SALAZARISMO E AS RELAÇÕES ENTRE BRASIL E PORTUGAL NA REVISTA LUSO-BRASILEIRA (1961-1979)}

\section{CRISTINA IUSKOW}

Portugal irá acentuar suas relações por diversos meios, e as publicações, inclusive as revistas de variedades, por exemplo, também farão parte dessas estratégias de inclusão, aproximação e ligação do Estado Novo com o emigrado e apoiador do regime português, no Brasil. As revistas poderiam ser um forte elo entre Portugal e o português ausente, pois poderiam envolver toda a família nos mesmos temas que vão de culinária até ações do governo de Salazar. Ao mesmo tempo em que atrai a mulher emigrada, com os temas tradicionalmente a ela direcionados, é dada a leitura também dos homens, pois aborda temáticas políticas e econômicas. A RLB pode-se dizer que possui estas características, está direcionada a todos na família, e diante disso é possível caracterizá-la como uma revista de variedades. Como afirma Tania de Luca ${ }^{\text {XVIII }}$, apesar de muitas revistas se autodenominarem "de variedades", é possível perceber a intenção de atingirem públicos diversos, pois eram ao mesmo tempo, femininas, masculinas, infantis, esportivas, pedagógicas, educacionais, voltadas ao teatro, rádio, cinema, religião e acrescentaria aqui também, política. Assim, nesta composição de temas e públicos, os editores tem um papel crucial, pois terão a função de reunir os redatores, imagens e notícias, que contrariamente ao que se poderia pensar em relação às revistas, está longe da "neutralidade". Conforme afirma Jean François Sirinelli, as revistas são "um lugar precioso para a análise do movimento das ideias". XIX

As ideias políticas, religiosas, morais entre outras, estão espalhadas nas páginas destas publicações, nas variadas notícias e conteúdos e muitas vezes passam sem serem notadas. Continua Sirinelli "uma revista é antes de tudo um lugar de fermentação intelectual e de relação afetiva, ao mesmo tempo viveiro e espaço de sociabilidade, e pode ser entre outras abordagens, estudada nesta dupla dimensão" XX A reunião de um grupo de intelectuais em torno da Revista Luso-Brasileira cria esses espaços de sociabilidade, formador e divulgador de ideias que naquele momento fermentavam no espaço político nacional e internacional, sobretudo no que concerne à relação entre Brasil, Portugal e as colônias africanas.

A textualidade da publicação aqui pesquisada se direciona ao público em geral, mas é possível perceber que privilegia especialmente o público português distante, buscando criar um laço com eles e entre eles. As matérias na sua maioria são voltadas ao público português nesses primeiros anos da revista. Ao intitular uma matéria Belezas e costumes de Portugal e junto dela uma foto do rio Tejo, o editor está ao mesmo tempo trazendo uma recordação para o leitor português e o conhecimento das terras portuguesas para o leitor brasileiro. No texto citado, o próprio Mario Dias escreve sobre as belezas e encantos de cidades em Portugal, sobre as festas e sobre locais. Registro que se apresenta corriqueiro e sem importância, todavia transporta uma carga emocional e de forte enaltecimento da nacionalidade portuguesa. Por meio destas narrativas as publicações deste tipo sustentam a identidade portuguesa, pois trazem à lembrança o passado no além-mar, os locais que os ligam a Portugal e ao que compõem o ser português. "Ser português e afirmá-lo é, portanto, para o imigrante, um traço que, para além de definir a sua identidade, o distingue,[...] da sociedade envolvente", ${ }^{\mathrm{XXI}}$ lembra Paulo. Buscar uma distinção e manter essa distinção, criar um liame entre os portugueses emigrados e ainda construir uma identidade portuguesa como apoiadores do regime na ex-colônia, era o que desejava o regime português para os portugueses no Brasil. Isso ocorria com mais força e nitidez em cidades maiores como o Rio de Janeiro e São Paulo, onde havia um grupo maior e mais homogêneo de portugueses. Em 


\section{LAÇOS TRANSATLÂNTICOS: O SALAZARISMO E AS RELAÇÕES ENTRE BRASIL E PORTUGAL NA REVISTA LUSO-BRASILEIRA (1961-1979)}

\section{CRISTINA IUSKOW}

Florianópolis, no entanto, o grupo de lusos era disperso e muitas vezes indiferente à agremiação, contudo a publicação, por meio do editor procura realizar tal agremiação, no sentido de trazer Portugal aos seus patrícios.

Vários são os temas que procuram por esse liame constituindo muitos dos textos da revista. Como se vê na seção Curiosidades para você em que o tema é novamente Portugal, e mais explicitamente ainda na seção Portugal em Marcha em que quatro notícias políticas sobre o país se apresentam e numa delas a situação da questão colonial com o título Benção Norte-americana - A penetração do comunismo em Angola. Esse é um tema que será recorrente na RLB e é possível perceber a posição política colonialista adotada pela revista, em concordância com o direcionamento do regime português. Para Paulo: "[...] a cultura popular, juntamente com o culto da história ou profissões de fé ideológicas, transforma-se em elemento de agregação e de um sentimento de 'nacionalidade' que se torna mais forte fora de Portugal". XXII As "profissões de fé ideológicas" a que se refere a autora, no caso da revista, apresentam-se repetidamente quando esta se posiciona a favor do colonialismo, e a favor do Estado Novo em Portugal, ou na defesa das ações governamentais de Salazar. Não menos importante que as profissões de fé como elemento do "sentimento de nacionalidade", haverá o culto da história que é outra das temáticas bastante recorrentes nas páginas da Luso-Brasileira. Sentimento de nacionalidade que passa pela capacidade de imaginar a nação, conforme afirma Benedict Anderson. XXIII Imaginar a nação distante, a comunidade portuguesa espalhada pelo "império ultramarino" formador da nação, imagem esta que deveria ser resguardada e estimulada por meio de imagens e lembranças da sua história.

$\mathrm{Na}$ matéria intitulada Glórias para o Brasil e Portugal, o texto em questão, escrito por Mário Dias, aborda os "heróis" do ar portugueses, Gago Coutinho e Sacadura Cabral, que em 1922 retornavam do Brasil na primeira viagem aérea do Atlântico Sul. Narrava-se: "A cidade [Lisboa] despertava para o contentamento, o que vinha provar estar o Brasil mais unido a Portugal, pois de futuro os aviões cruzariam o Atlântico". XXIV O texto integral relembra aos portugueses os seus personagens importantes, seus "heróis", uma forma de imaginar a nação, e este pequeno trecho em particular evidencia a união almejada entre os dois países. Na mesma página, numa pequena nova seção Caricatura lembra do "herói" dos ares do Brasil, Santos Dumont. Uma página para relembrar aos brasileiros e portugueses seus heróis dos ares, dos personagens que permeiam a história dos "países irmãos".

A imagem de Salazar vai aos poucos sendo inserida na publicação, trazendo ao imaginário social de leitores e leitoras portugueses e brasileiros a presença de um Salazar que fala aos seus cidadãos, em Portugal ou fora dele. Parte-se do conceito de imaginário social proposto por Bronislaw Baczko, o qual o entende como

[...] um aspecto da vida social, da atividade global dos agentes sociais, cujas particularidades se manifestam na diversidade dos seus produtos. Os imaginários sociais constituem outros tantos pontos de referência no vasto sistema simbólico que qualquer colectividade produz e através da qual, como disse Mauss, ela se percepciona, divide e elabora os seus próprios objectivos. É assim que, através dos seus imaginários sociais, uma colectividade designa a sua identidade; elabora uma certa representação de si; estabelece a distribuição dos papéis e das posições sociais; exprime e impõe crenças comuns; constrói uma espécie de código de "bom comportamento", 


\section{LAÇOS TRANSATLÂNTICOS: O SALAZARISMO E AS RELAÇÕES ENTRE BRASIL E PORTUGAL NA REVISTA LUSO-BRASILEIRA (1961-1979)}

\section{CRISTINA IUSKOW}

designadamente através da instalação de modelos formadores tais como o do "chefe", o "bom súbdito", o "guerreiro corajoso", etc. XXV

A partir daí é possível compreender como o imaginário social do emigrante português reproduz e reforça seus gostos e sentimentos, mesmo num país distante, mesmo inserido numa cultura diferente da sua. A publicação ao remeter as imagens e contextos da nação portuguesa nas matérias realiza um trabalho de fortalecer a identidade nacional lusa. $\mathrm{E}$ assim, já no seu primeiro número, abaixo de uma visível foto de Salazar, inicia-se o texto Salazar falando à Nação.

Falando para todos portugueses, o Sr. Prof. Oliveira Salazar se dirigiu à
nação, com um notável discurso que foi um exemplo de patriotismo, de
inteligência e de dignidade. Esclareceu a nação quanto ao presente e ao
futuro, contou serenamente o panorama atual do mundo, as críticas e ofensas
ao Ultramar Português, a sua voz foi a voz da Pátria, avisando os atrevidos
que Portugal não dorme, o alerta e a nossa força, será o suficiente para dar ao
mundo uma lição de que somos vigilantes e unidos aos povos que nos
admiram e respeitam. XXVI

O texto não tem a data nem local no qual Salazar fala à nação, seu discurso atravessa o tempo e as fronteiras. $\mathrm{O}$ importante aqui é que sua mensagem chega por meio de suas palavras aos portugueses emigrados, apresentando os problemas que Portugal ainda sofre no cenário internacional por conta de sua política no Ultramar, lembrando que há países que o criticam e ofendem devido a esta política. E adverte que a ligação com os povos que o "admiram e respeitam" é a sua força. O Brasil é um desses países, sua histórica amizade com Portugal deve ser reforçada para que ele consiga perseverar na manutenção da política africana. As relações com o Brasil começam a sofrer as consequências da Política Externa Independente $(\mathrm{PEI})^{\mathrm{XXVII}}$, e, portanto as relações com a comunidade portuguesa no Brasil se tornam estratégicas para que a sua influência política não esmoreça. Havia uma preocupação grande do regime do Estado Novo com relação às guerras de independência iniciadas em Angola, portanto mais ainda os laços de amizade com o Brasil necessitavam ser fortalecidos, sobretudo no que diz respeito à atuação do Brasil na ONU. A revista se colocava como intermediária da voz de Salazar entre os portugueses no Brasil. Ao mesmo tempo em que atingia os brasileiros sensibilizando-os para os propósitos do salazarismo do qual a revista se colocava como defensora.

As temáticas políticas da Luso-Brasileira, citadas anteriormente, são sucedidas na página seguinte por três receitas culinárias: bacalhau ao forno, pastéis de bacalhau e caldo verde, receitas tipicamente portuguesas. As receitas culinárias neste contexto são elementos que compõem a identidade portuguesa e sua veiculação na revista traz para a realidade do português emigrado as lembranças da sua terra natal, mantendo o imigrante conectado as vivências cotidianas passadas em Portugal.

O trabalho com publicações como revistas exige que se atente para algumas questões como, por exemplo, o público a que se direcionam, as temáticas envolvidas na publicação, quem escreve no periódico, por vezes as posições políticas dos redatores, da direção e também qual o intuito do periódico quando da sua publicação. Além disso, não se pode esquecer que os periódicos estão inseridos em um mercado, e sua narrativa é direcionada a um público para ser consumida e comercializada, gerando lucros para 


\section{LAÇOS TRANSATLÂNTICOS: O SALAZARISMO E AS RELAÇÕES ENTRE BRASIL E PORTUGAL NA REVISTA LUSO-BRASILEIRA (1961-1979)}

\section{CRISTINA IUSKOW}

seus produtores. A narrativa da revista pode ser pensada como expressando três "vozes" que na narrativa se apresentam primeiramente como: a voz da revista, unívoca, consonante, voltada à temáticas variadas; a voz do autor do texto, que acompanham a narrativa da revista e são selecionadas para reproduzirem a linha política da revista; por último há a voz dos atores e grupos sociais apresentados nas matérias da revista, os quais se tornam vozes que são retratadas de acordo com a linha ideológica da publicação. As revistas se apresentam na sua particularidade como imprensa periódica e também conceitualmente muito mais como entretenimento do que informação, no entanto muitas delas conseguiram ao longo do tempo agradar a vários públicos. Esse público variado era atraído muitas vezes por meio de capas diversas a um tema por vezes mais divertido ou ligado a pessoas da sociedade, no entanto temas que tratavam de outros assuntos se encontravam somente no interior da publicação, que apresentava por sua vez questões concernentes normalmente à política e economia.

$\mathrm{Na}$ seção intitulada $O$ Brasil em Marcha a matéria exibida aborda a política econômica do presidente Jânio Quadros. "Para salvar o país da ruína total, endividado que está, o Presidente Jânio Quadros promoveu a reforma cambial. Acabou com o dólar de privilégio que enriquecia uns poucos e empobrecia a Nação". XXVIII A RLB faz uma matéria bastante elogiosa dos feitos que vem fazendo Quadros na economia. Não se percebe nesta referência a Jânio nenhum tipo de ressentimento acerca da sua política externa crítica aos posicionamentos do governo de Salazar na África ou as suas relações econômicas estabelecidas com países socialistas. E ao fim da matéria este trecho que confirma a concordância da revista a sua política econômica: "Quanto ao Presidente, que prossiga em sua dura missão de sanear a economia nacional de seus vícios e defeitos que a têm comprometido". XXIX

Na continuação a Luso-Brasileira, em texto escrito por Mario Fernandes Dias, aborda um conjunto de temas bastante emblemáticos e de maneira simbólica neste primeiro número. O extenso texto intitula-se Relembrando o Infante Santo quando Portugal e Brasil deram as mãos, e nele Dias relembra JK, do Infante Dom Henrique e da saudade da terra. A matéria começa relembrando a visita de Juscelino a Portugal, que se realizou em agosto de 1960 nas comemorações do V Centenário do Infante Dom Henrique. Mario Dias relembra um episódio ocorrido oito meses atrás, mas não informa a data na matéria: "Vai longe aquele dia em que o povo luso, recebia a ilustre visita do D. Juscelino de Oliveira. Tendo em vista que a nossa revista é um laço de união que une os dois povos irmãos, eu pretendo gravar esse acontecimento na lembrança de milhares de portugueses". XXX A função da revista é a de manter viva na lembrança dos portugueses a ligação fraternal entre lusos e brasileiros, a qual foi uma marca de governos passados, e que deveria continuar sendo a marca entre os dois povos. Prossegue: "O Brasil visitava a terra mãe, ia levar-lhe um abraço de saudades de outros tantos portugueses, espalhados por este torrão brasileiro, por esta terra que Cabral descobriu" XXXI A saudade da terra é um tema recorrente na narrativa da revista, e como português emigrado, o editor acaba por colocar-se na condição de cidadão português saudoso da sua terra, mas que, no entanto atua como um representante do governo na ex-colônia, trabalhando para fortalecer o enlace entre os dois países.

E continua:

Lisboa viveu uma festa digna, o Tejo com as suas barquinhas, ao longe o monumento a Cristo-Rei, desta forma meu coração parece estar batendo fora 


\section{LAÇOS TRANSATLÂNTICOS: O SALAZARISMO E AS RELAÇÕES ENTRE BRASIL E PORTUGAL NA REVISTA LUSO-BRASILEIRA (1961-1979)}

\section{CRISTINA IUSKOW}

do normal, talvez porque estou recordando a minha terra natal, a minha querida e sempre bonita Lisbôa, as ruas limpas, o palácio de S. Bento onde mora o Sr. Presidente do Consêlho Dr. Oliveira Salazar, o professor que com a sua inteligência tem levado Portugal a destacar-se no mundo inteiro. ${ }^{\text {XXII }}$

Ao mesmo tempo em que expressa sua saudade da terra natal, o autor se coloca como voz que representa a de outros portugueses e portuguesas que estão longe de Portugal. Junto com a saudade e das belezas das ruas de Lisboa, revela sua impressão positiva do ditador Salazar que nestas linhas são bastante evidentes. E ainda neste tom elogioso: "Pela mão de tão brilhante alma o meu Portugal distante continuará em paz e em prosperidades. Além de tudo a minha missão é unir mais os dois povos irmãos". XXXIII E mais uma vez salienta a sua missão, em primeira pessoa, que é também a da publicação. A referência aos heróis portugueses se apresenta neste número de forma incisiva, e ao abordar o Infante Dom Henrique o refere como mais um herói que une brasileiros e portugueses. Salienta:

Ele marcou com a sua inteligência o rumo do mundo nos 500 anos seguintes ao do seu nascimento. Com a sua idéia, os missionários foram para a África, ali espalharam a semente das Sagradas Escrituras. Deus se serviu do Infante para evangelizar outras gentes e desbravar outras terras.

A história de Portugal está repleta de heróis, as suas páginas nos contam as dinastias, os reis e suas gerações, e depois o descobrimento do Brasil, este mundo novo na sua marcha de progresso e paz. ${ }^{\text {XXIV }}$

O descobrimento do Brasil está ligado a este evento que inaugura um tempo de "progresso" para esta terra. A revista, como uma publicação que é distribuída também em colônias portuguesas na África, age como defensora da atividade colonizadora, contrária aos movimentos de independência que começam a se estabelecer e mobilizar em Angola. Elogiar o empreendimento da Escola de Sagres e toda a atividade colonizadora portuguesa, bem como o "progresso" daí advindo para a ex-colônia Brasil é uma forma de corroborar com o regime salazarista. Ao mesmo tempo que elogia a aproximação do ex-presidente JK a Portugal e a toda a amizade construída entre eles, mostra aos leitores brasileiros o quanto é justificável essa união, pois o Brasil teria muito a reconhecer pelo trabalho dos "heróis" portugueses.

Ao apresentar o turismo na cidade, a RLB convida a explanar o tema o colunista e jornalista Osvaldo Melo, o qual possuía uma coluna diária no jornal O Estado. Em texto intitulado Florianópolis e o Turismo ele apresenta uma cidade que está despertando para o turismo com a sua "natureza exuberante, luxuriosa, riquíssima" XXXV O texto expõe os aspectos das belezas naturais da cidade propícias para a recepção dos turistas, no entanto aponta alguns entraves para que essa recepção ocorra. Escreve sobre Florianópolis: "Lugar próprio para o turismo será aquele que, além de apresentar tudo que possa recrear e distrair o turista, ainda possa contar com boas estradas, acomodações se bem que não luxuosas, mas que apresente pelo menos, conforto, higiene e bom passadio". XXXVI Seu desejo é de que melhorias e modernizações ocorram na cidade para que se torne lugar próprio para o turismo. Continua: "Os homens estão preparando-se para encaixar a admirável tela em moldura condigna e rica".XXXVII Reinaldo Lohn afirma que o colunista Osvaldo Melo, na sua coluna no jornal o Estado "durante anos pregou o crescimento a qualquer custo da cidade, incentivando um verdadeiro 'bota-abaixo' dos antigos edifícios do centro [...]”. XXXVIII Posição que se 


\section{LAÇOS TRANSATLÂNTICOS: O SALAZARISMO E AS RELAÇÕES ENTRE BRASIL E \\ PORTUGAL NA REVISTA LUSO-BRASILEIRA (1961-1979)}

\section{CRISTINA IUSKOW}

coaduna com o texto escrito para a Luso-Brasileira e que ao mesmo tempo demonstra, em princípio, o posicionamento político do corpo de jornalistas e escritores que compunham o quadro da publicação neste seu período inicial. E confirmando essa postura, prossegue Melo, "Florianópolis, quero crer, está sendo descoberta para se tornar cidade do turismo. Mas para que o seja de fato, e em verdade, devem se dar as mãos governo e iniciativas particulares". XXXIX Qual o preço para essa descoberta e para o dar-se as mãos entre governo e iniciativa privada, ainda não se sabe.

$\mathrm{Na}$ continuação a temática passa a ser Portugal. Ao noticiar informações políticas e sociais sobre o país luso na seção Notícias do Portugal a revista faz apontamentos sobre a situação da guerra colonial em Angola relatando o

\footnotetext{
Gesto louvável em favor das crianças de Angola, promoção do nosso colega Diário Popular. Todos os lares de Portugal se abrem numa iniciativa digna, para serem recebidas as crianças angolezas. Até que seja amainado o temporal dos terroristas que matam e atacam as aldeias das famílias da colônia, essas crianças estarão em segurança. ${ }^{\mathrm{XL}}$
}

Novamente a RLB se posicionando em relação às guerras coloniais, e ao abordar o tema vale-se do termo "terroristas" se referindo aos movimentos de independência em Angola, opondo colonos a nativos que lutavam pela autodeterminação, classificando-os como terroristas. E em outro pequeno texto desta seção prossegue:

Continuam seguindo para a província ultramarina de Angola mais tropas com o propósito de repelir os invasores. Sabemos que os nossos colonos estão em perigo, mas os portugueses jamais perderam uma batalha. Daqui enviamos o nosso louvor aos bravos patrícios que marcham para a frente de combate e que Deus os proteja sempre. ${ }^{\mathrm{XLI}}$

Ao mesmo tempo que apresenta a notícia se posiciona em relação a ela, a partir da postura que toma a respeito da situação da guerra colonial. Coloca-se na defesa dos colonos em Angola, não do conjunto da população de Angola. A Luso-Brasileira apresenta uma posição oficial, em comum acordo com a postura do regime de Salazar em relação às colônias, e procura reunir em torno de si os portugueses emigrados no apoio a essa ideia contra a independência de Angola. Não quer unicamente oferecer a notícia de forma despolitizada, mas reforçar a sua posição de maneira a aglutinar os que estiverem de acordo com ela.

São comuns os textos que descrevem a vida do português Mario Fernandes Dias, editor da revista, além de cidades, cultura e costumes portugueses. No texto Lisboa da minha saudade ele se refere a Lisboa seu "torrão natal", a "terra dos heróis marinheiros". Comenta sobre o dia a dia da vida do comércio do peixe em Lisboa e a vida corrida dos operários na hora do almoço, sobre o assunto das conversas dos amigos que tocam em temas como o futebol do Benfica ou a viagem do homem à Lua. Ao discorrer sobre o fado afirma que "Lisboa tem coisas notáveis que jamais poderei esquecer. Os moços adoram o fado, e não há cão nem gato que não conheça a Amália e o Alberto Ribeiro" XLII Estas temáticas fazem pensar com Heloisa Paulo quando afirma que

A 'Pátria' é [...] um ideal, uma imagem, ou uma utopia que a distância torna, cada vez mais, ‘intocável'. Como ‘idealização', ela não é passível de críticas, 


\section{LAÇOS TRANSATLÂNTICOS: O SALAZARISMO E AS RELAÇÕES ENTRE BRASIL E PORTUGAL NA REVISTA LUSO-BRASILEIRA (1961-1979)}

\section{CRISTINA IUSKOW}

sendo impossível, de imediato, a aceitação de uma outra imagem mais real, que pusesse fim à esta visão. Venerada, a 'Pátria' é, portanto, motivo de culto, traduzido numa devoção à aldeia natal, mas que passa por referenciais mais 'intelectualizados', como a história, com as suas datas e heróis oficiais. ${ }^{\mathrm{XLIII}}$

Este trecho é bastante significativo e exprime de forma elucidativa a relação que se cria entre o emigrado e sua "Pátria" distante, a intensidade de sentimentos que se apresentam quando se trata de falar da sua terra natal, idealizada e "intocável". O país que lá ficou não é passível de problemas políticos nem sociais. Portugal será mais do que nunca motivo de veneração aos olhos do emigrado, não há espaço para críticas, pois era preciso lembrar também que o emigrado é um representante de Portugal no país para o qual emigrou e, portanto, cabia-lhe fazê-lo da melhor forma, para mostrar ao mundo a grandeza do "império português".

A Revista Luso-Brasileira era publicada na cidade de Florianópolis, para um público leitor de brasileiros, mas também para os portugueses que viviam na cidade. Havia em Florianópolis uma comunidade lusa não muito expressiva, mas que se esforçava por manter sua coesão ao conservar uma proximidade física nos bairros da cidade. Por meio de conversas iniciais com um casal de portugueses habitantes de Florianópolis, residentes desde a década de 1960 na capital, foi possível perceber que havia aqui um grupo que mantinha contatos e procurava comprar ou alugar casas próximas dos seus conhecidos portugueses. Concomitantemente a reunião da comunidade portuguesa, os editores vão formando uma rede de sociabilidades que vai associando grupos variados de pessoas para publicarem na revista e que abordem temas variados. Esporte é um desses temas e para escrever sobre ele será convidado Gilberto Paiva que no seu primeiro texto na Revista Luso-Brasileira, irá discorrer sobre o Clube de Regatas Vasco da Gama "prestigiosa agremiação militante no esporte guanabarino [...]. Nascido na rua da Saúde a custa de esforços de portugueses e brasileiros, unidos num só desejo, numa só intenção [...]" XLIV . A importância deste clube para a comunidade luso-brasileira foi já exortada por José Honório Rodrigues em 1961, quando afirma que

\footnotetext{
sem querer causar surpresa, uma das melhores e mais frutíferas atividades da colônia se faz, no Rio de Janeiro, por intermédio do Clube de Regatas Vasco da Gama. [...] o clube gloria as origens portuguesas da nação com o nome de um descobridor português [...] inculca, na consciência coletiva popular, a ideologia da herança cultural pelo simbolismo da competição e pela dramatização da vitória. [...] ela representa e significa todo um conjunto de valores que convém a Portugal manter vivo no Brasil. ${ }^{\mathrm{XLV}}$
}

O esporte será mais um elemento da identidade portuguesa que fará a ligação dos imigrantes com os simbolismos da terra lusa os quais fazem o papel de unir os portugueses em torno da sua nacionalidade e dos "valores" portugueses.

Com referência ao Natal de 1961 é publicado o último número do ano. Neste número pode-se ler uma informação importante, que é a "Parceria Antonio Maria Pereira. Livraria Editora, fundada há 113 anos. Nosso agente exclusivo de vendas em Lisboa-Portugal". XLVI Antonio Maria Pereira, presidente desde 1940 até 1957 do Grémio Nacional dos Editores e Livreiros (GNEL) é, segundo Nuno Medeiros “Adepto, desde a primeira hora, do ideário e da figura de Salazar. [...] É durante o exercício do 


\section{LAÇOS TRANSATLÂNTICOS: O SALAZARISMO E AS RELAÇÕES ENTRE BRASIL E PORTUGAL NA REVISTA LUSO-BRASILEIRA (1961-1979)}

\section{CRISTINA IUSKOW}

seu longo mandato que as relações institucionais com o poder se normalizam, pelo menos do ponto de vista associativo". XLVII A revista constrói uma rede de sociabilidades e negociações no Brasil e em Portugal que se liga a órgãos e grupos aliados aos seus escopos e posturas políticas nos dois países. Talvez, pela organização da estrutura da revista, que não costuma seguir um padrão gráfico, não seja possível perceber um projeto bem definido, no entanto estas conexões com grupos e pessoas em Portugal e no Brasil possibilitam entrever que existe um projeto político esboçado para essa publicação.

Abordar as belezas naturais e história de Portugal na Luso-Brasileira é uma forma de falar sobre a cultura nacional, buscando uma "narrativa da nação" conforme afirma Stuart Hall, as quais "fornecem uma série de histórias, imagens, panoramas, cenários, eventos históricos, símbolos e rituais nacionais que simbolizam ou representam as experiências partilhadas, as perdas, os triunfos e os desastres que dão sentido à nação". XLVIII Tais narrativas são veiculadas na revista de forma que a nação se apresente não "apenas [como] uma entidade política, mas [como] algo que produz sentidos - um sistema de representação cultural". XLIX Desse modo ao falar sobre as belezas de Portugal e da sua história, reforça-se o sentimento de lusitanidade entre os portugueses que estão fora do seu país de origem e cria-se ao mesmo tempo uma identificação destes indivíduos à sua nação, à sua cultura e a tudo aquilo que envolve o ser português no início dos anos 1960 no interior do regime salazarista, qual seja, defender o caráter expansionista e conquistador português, e a legitimidade das suas províncias ultramarinas. Ser português fora de Portugal significava, portanto abraçar essa "causa" e defendê-la, sobretudo estando no Brasil.

\section{Notas}

\footnotetext{
${ }^{\text {I }}$ Doutoranda em História pela Universidade do Estado de Santa Catarina. Este texto foi produzido com o financiamento da Capes. E-mail: cristina.iuskow@gmail.com.

${ }^{\text {II }}$ MARTINS, Ana Luiza. Revistas em Revista: Imprensa e Práticas Culturais em Tempos de República. São Paulo: Edusp, 2008, p.21.

III Foi um jornal de grande tiragem, publicado em Lisboa, entre 22 de Setembro de 1942 e 28 de Setembro de 1991 que tinha como grande objetivo avivar a consciência nacional. [...] Fundado em 1942 por António Tinoco, o vespertino de tendência pró-Estado Novo, era propriedade da empresa Sociedade Industrial de Imprensa, Ltda., [...]. Conhecido como o jornal de maior expansão no mundo português, o Diário Popular alcançou desde cedo uma grande tiragem (cerca de cem mil exemplares), uma grande implantação junto dos leitores e uma base publicitária muito forte, traduzindo-se assim em resultados lucrativos." (ROSA, 2014, p.45)

IV Abreviatura utilizada para Revista Luso-Brasileira.

${ }^{\mathrm{V}}$ Revista Luso Brasileira, $\mathrm{n}^{\circ} 1$, maio, 1961, p.2.

${ }^{V I}$ KOSELLECK, Reinhart. Futuro Passado: contribuição à semântica dos tempos históricos. Rio de Janeiro: Contraponto: Ed. PUC-Rio, 2006, p.310.

${ }^{\mathrm{VII}}$ LOURENÇO, Eduardo. A nau de Ícaro e Imagem e miragem da lusofonia. São Paulo: Companhia das Letras, 2001, p.136-137.

VIII LOURENÇO, 2001, p.158.

IX PAULO, Heloísa. "Aqui também é Portugal": A colônia Portuguesa do Brasil e o Salazarismo.

Coimbra: Quarteto, 2000, p. 44.

${ }^{X}$ PAULO, 2000, p.53.

${ }^{\mathrm{XI}}$ PAULO, 2000, p.72.
} 


\title{
LAÇOS TRANSATLÂNTICOS: O SALAZARISMO E AS RELAÇÕES ENTRE BRASIL E PORTUGAL NA REVISTA LUSO-BRASILEIRA (1961-1979)
}

\author{
CRISTINA IUSKOW
}

XII Preâmbulo do Decreto $\mathrm{n}^{\circ} 16.782$, de 27 de Abril de 1929, in: Diário de Governo, $\mathrm{I}^{\mathrm{a}}$ série, $\mathrm{n}^{\mathrm{o}} 95$,
p.1047. Desde 1929 os decretos que estabelecem as exigências para os emigrantes vão sendo alterados,
pois na prática essas exigências não são atendidas. Em 1941 o Anuário estatístico mostra que naquele ano
607 emigrantes que entraram no Brasil eram analfabetos, cerca de 1/4 do total, apesar das disposições legais contrárias em ambos os países. (PAULO, 2000).

XIII PAULO, 2000, p.79.

XIV O Boletim de Emigração, publicado pelo Comissariado Geral dos Serviços de Emigração, é destinado a fornecer informações gerais para quem emigra, como descrição dos contratos de patronatos de emigrantes, índice de preços das passagens, listagem dos agentes autorizados, possibilidade de colocação para os emigrantes e decretos relacionados com a emigração. Os panfletos de propaganda da Junta de Emigração, são destinados a elucidar o emigrante a respeito do processo emigratório. (PAULO, 2000, $86)$.

XV JUNTA DE EMIGRAÇÃO apud PAULO, 2000, p.89.

${ }^{\mathrm{XVI}}$ FERNANDES apud MACIEL, Cármen L. F. A Construção da Comunidade Lusófona a Partir do

Antigo Centro. Micro-Comunidades e Práticas da Lusofonia. Dissertação, UNL, 2010, p 30.

${ }^{X V I I}$ LANG apud OLIVEIRA, Lúcia Lippi (CPDOC/FGV). Portugal e Brasil: uma relação tão delicada. ANPUH - XXII SIMPÓSIO NACIONAL DE HISTÓRIA, João Pessoa, 2003, p.3.

XVIII DE LUCA, Tânia Regina. A Revista do Brasil: um diagnóstico para a (N)ação. São Paulo:

Fundação Editora UNESP, 1999, p.122.

XIX SIRINELLI, Jean-François. Os intelectuais. In. RÉMOND, René. (Org.) Por uma História Política.

Rio de Janeiro: Editora FGV, 2003, p.249.

${ }^{\mathrm{xX}}$ SIRINELLI, 2003, p. 249.

XXI PAULO, 2000, p.250.

XXII PAULO, 2000, p.160.

XXIII ANDERSON, Benedict. Nação e consciência nacional. São Paulo: Ática, 1989.

XXIV Revista Luso-Brasileira, ${ }^{\circ}{ }^{1}$, maio, 1961, p.7.

Xxv BACZKO, Bronislaw. "A imaginação social” In: Leach, Edmund et Alii. Anthropos-Homem.

Lisboa, Imprensa Naciona//Casa da Moeda, 1985, p.309.

XXVI Revista Luso-Brasileira, ${ }^{\circ} 1$, maio, $1961, \mathrm{p} .10$.

XXVII PEI (Política Externa Independente) foi a expressão atribuída as novas atribuições da política exterior do Brasil durante os governos da Jânio Quadros e João Goulart entre 1961 e 1964. (PETROCCHI, 2015, p.82).

XXVIII Revista Luso-Brasileira, $\mathrm{n}^{\circ} 1$, maio,1961, $\mathrm{p} ; 12$.

XxIX Revista Luso-Brasileira, $\mathrm{n}^{\circ} 1$, maio,1961, p.12.

Xxx Revista Luso-Brasileira, ${ }^{\circ} 1$, maio, 1961, p.15.

Xxxi Revista Luso-Brasileira, ${ }^{\circ} 1$, maio, 1961, p.15.

XXXII Revista Luso-Brasileira, $\mathrm{n}^{\circ} 1$, maio, 1961, p.15.

XXXIII Revista Luso-Brasileira, ${ }^{\circ}{ }^{1}$, maio, 1961, p.15.

Xxxiv Revista Luso-Brasileira, $\mathrm{n}^{\circ} 1$, maio, 1961, p.15.

${ }^{x x x v}$ Revista Luso-Brasileira, $n^{\circ}$ 2, jun/jul, 1961, p.18.

XxxvI Revista Luso-Brasileira, no2, jun/jul, 1961, p.18.

XxxvII Revista Luso-Brasileira, nº, jun/jul, 1961, p.18.

XxxvIII LOHN, Reinaldo L. Pontes para o Futuro: relações de poder e cultura urbana - Florianópolis, 1950 a 1970. Tese. UFRGS, 2002, p.243.

XxxIx Revista Luso-Brasileira, ${ }^{\circ} 1$, mai, 1961, p.15.

${ }^{\mathrm{XL}}$ Revista Luso-Brasileira, $\mathrm{n}^{\circ}$ 2, jun/jul, 1961, p.20.

${ }^{\mathrm{XLI}}$ Revista Luso-Brasileira, ${ }^{\circ}$ 2, jun/jul, 1961, p.20.

XLII Revista Luso-Brasileira, n.3, ago, 1961, p.13.

XLIII PAULO, H. 2000, p.274.

XLIV Revista Luso-Brasileira, ${ }^{\circ}$ 4, set/out, 1961, p.4.

XLV RODRIGUES, José H. Brasil e África: outro horizonte. Rio de Janeiro: Civilização Brasileira, 1961, p. 361.

${ }_{\mathrm{XLVI}}$ Revista Luso-Brasileira, nº5, dez, 1961, p.2.

XLVII MEDEIROS, Nuno. Editores e Estado Novo: o lugar do Grémio Nacional dos Editores e Livreiros.

Análise Social, vol. XLIII (4. $\left.{ }^{\circ}\right), 2008,795-815 . p .803$. 


\section{CRISTINA IUSKOW}

XLVIII HALL, S. A identidade cultural na pós-modernidade. Rio de Janeiro: Lamparina, 2014, p. 31. XLIX HALL, 2014, p.30.

\section{Referências}

ANDERSON, Benedict. Comunidades Imaginadas: Reflexões sobre a origem e a Expansão do Nacionalismo. Lisboa: Edições 70, 2005.

BACZKO, Bronislaw. “A imaginação social” In: Leach, Edmund et Alii. AnthroposHomem. Lisboa, Imprensa Nacional/Casa da Moeda, 1985.

DE LUCA, Tânia Regina. A Revista do Brasil: um diagnóstico para a (N)ação. São Paulo: Fundação Editora UNESP, 1999.

HALL, Stuart. A identidade cultural na pós-modernidade. Rio de Janeiro: Lamparina, 2014, p. 31.

LOHN, Reinaldo L. Pontes para o Futuro: relações de poder e cultura urbana Florianópolis, 1950 a 1970. Tese. UFRGS, 2002.

LOURENÇO, Eduardo. A nau de Ícaro e Imagem e miragem da lusofonia. São Paulo: Companhia das Letras, 2001.

MACIEL, Cármen Liliana Ferreira. A Construção da Comunidade Lusófona a Partir do Antigo Centro. Micro-Comunidades e Práticas da Lusofonia. Dissertação de Doutoramento em Sociologia, Universidade Nova de Lisboa, 2010.

MARTINS, Ana Luiza. Revistas em Revista: Imprensa e Práticas Culturais em Tempos de República. São Paulo: Edusp, 2008, p.21.

MEDEIROS, Nuno. Editores e Estado Novo: o lugar do Grémio Nacional dos Editores e Livreiros. Análise Social, vol. XLIII (4. $\left.{ }^{\circ}\right)$, 2008, 795-815. Disponível em: $<$ http://analisesocial.ics.ul.pt/documentos/1228400187K9rAL4ds1Pv08SB5.pdf $>$. Acesso em 30 ago 2017.

OLIVEIRA, Lúcia Lippi (CPDOC/FGV). Portugal e Brasil: uma relação tão delicada. ANPUH - XXII SIMPÓSIO NACIONAL DE HISTÓRIA, João Pessoa, 2003.

Disponível em: $<$ http://anais.anpuh.org/wpcontent/uploads/mp/pdf/ANPUH.S22.409.pdf> Acesso em 21 jul 2017.

OLIVEIRA, Sarah Luna de. Contribuições de Gilberto Freyre para a construção de uma política externa brasileira em defesa do colonialismo português (1950-1960). Reb. de Estudios Brasileños, I Primer Semestre 2015 I, Volumen 2 - Número 2. pp. 101-112. Disponivel em:

$<$ https://dialnet.unirioja.es/servlet/articulo? codigo $=5037311>$ Acesso em 15 jul 2017.

PAULO, Heloísa. "Aqui também é Portugal": A colônia Portuguesa do Brasil e o Salazarismo. Coimbra: Quarteto, 2000. 


\section{CRISTINA IUSKOW}

PETROCCHI, Renato. San Tiago Dantas: a Política Externa como instrumento de reforma social e de democracia. Carta Internacional (USP), v. 10, p. 81-96, 2015. Disponível em: <https://cartainternacional.abri.org.br/Carta/article/viewFile/275/247> Acesso em 30 ago 2017.

ROSA, Joana Catarina Vieira da. Expresso: Um projeto de renovação no fim do Marcelismo Dissertação. Escola Superior de Comunicação Social - Instituto Politécnico de Lisboa, 2014.

SIMPSON, Duncan. A Igreja Católica e o Estado Novo de Salazar. Locus: Revista de História, Juiz de Fora, v.18, n.1, p. 89-110 2012. Disponível em:

$<$ https://www.researchgate.net/profile/Duncan Simpson4/publication/306285760\%27

A_Igreja_Catolica_e_o_Estado_Novo_de_Salazar\%27/links/57e97c0f08aef8bfcc961a4

b/A-Igreja-Catolica-e-o-Estado-Novo-de-Salazar.pdf> Acesso em 15 jul 2017.

SIRINELLI, Jean-François. Os intelectuais. In. RÉMOND, René. (Org.) Por uma

História Política. Rio de Janeiro: Editora FGV, 2003.

\section{Fontes Consultadas}

REVISTA LUSO-BRASILEIRA números 1961 (1, 2, 3, 4, 5)

RODRIGUES, José Honório. Brasil e África: outro horizonte. Rio de Janeiro:

Civilização Brasileira, 1961.

QUADROS, Jânio. “A Nova Política Externa do Brasil” In. Revista Brasileira de

Política Internacional, Rio de Janeiro, ano IV, n ${ }^{\circ}$, dezembro de 1961. [On Line] 